\title{
On-Line Electrochemical Reduction of Disulfide Bonds: Improved FTICR-CID and -ETD Coverage of Oxytocin and Hepcidin
}

\author{
Simone Nicolardi, ${ }^{1}$ Martin Giera, ${ }^{1}$ Pieter Kooijman, ${ }^{1}$ Agnieszka Kraj, ${ }^{2}$ \\ Jean-Pierre Chervet, ${ }^{2}$ André M. Deelder, ${ }^{1}$ Yuri E. M. van der Burgt ${ }^{1}$ \\ ${ }^{1}$ Leiden University Medical Center (LUMC), Center for Proteomics and Metabolomics, 2300 RC, Leiden, The Netherlands \\ ${ }^{2}$ Antec, Zoeterwoude, The Netherlands
}
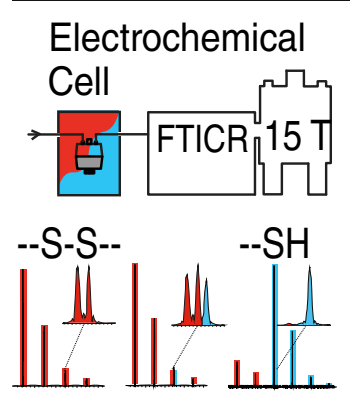

\begin{abstract}
Particularly in the field of middle- and top-down peptide and protein analysis, disulfide bridges can severely hinder fragmentation and thus impede sequence analysis (coverage). Here we present an on-line/electrochemistry/ESIFTICR-MS approach, which was applied to the analysis of the primary structure of oxytocin, containing one disulfide bridge, and of hepcidin, containing four disulfide bridges. The presented workflow provided up to $80 \%$ (on-line) conversion of disulfide bonds in both peptides. With minimal sample preparation, such reduction resulted in a higher number of peptide backbone cleavages upon CID or ETD fragmentation, and thus yielded improved sequence coverage. The cycle times, including electrode recovery, were rapid and, therefore, might very well be
\end{abstract} coupled with liquid chromatography for protein or peptide separation, which has great potential for highthroughput analysis.

Key words: Mass spectrometry, Ultrahigh resolution, FTICR-MS, Top-down analysis, Disulfide bond, Electrochemistry, Oxytocin, Hepcidin

Received: 24 May 2013/Revised: 25 July 2013/Accepted: 25 July 2013/Published online: 10 September 2013

\section{Introduction}

$\mathrm{P}$ rotein sequencing by tandem mass spectrometry (MS/MS) has evolved into a standard and widely applied method [1, 2]. The most common approach in MSbased proteomics involves digestion with specific enzymes after performing a reduction/alkylation step, referred to as bottom-up or peptide-centric readout [3-5]. The digestion step is often not applied for the analysis of "native" or endogenous peptides, and is even avoided for top-down protein MS [4, 6-10]. The analysis of "intact" peptides or proteins allows the characterization of one of the most common post-translational modifications (PTMs) in proteomics, namely disulfide bonds [11]. These bonds, or "S-S bridges", stabilize the three-dimensional structure of a protein and, therefore, are crucial elements for their biological function. On the other hand, disulfide bonds can also hinder MS/MSfragmentation in different ways. In an MS/MS-collision induced dissociation (CID) experiment primarily peptide backbone fragmentations are observed, with a preference for cleavages

Correspondence to: Yuri E. M. van der Burgt; e-mail: y.e.m.van_der_burgt@lumc.nl of the "weakest" amide bond, resulting in either $b$ - or $y$-ions [12]. In the presence of a disulfide bond, such backbone characterization is often hampered and thus poses a challenge for middleand top-down analysis of intact proteins. Also, proper assignment becomes difficult when the fragments themselves remain connected via an S-S bridge. With the introduction of electron capture dissociation (ECD) and later electron transfer dissociation (ETD), new possibilities emerged for fragmenting disulfide bonds $[13,14]$. In general, ECD is more effective than CID in cleaving S-S bonds, thus allowing for sequencing of regions that are involved in intra- or intermolecular linkages [15]. Nevertheless, even after cleavage of the S-S bond, the resulting "fragment ion" may still be intact because of the remaining connectivity in the peptide backbone. Consequently, off-line reduction of disulfide bonds with a reagent such as dithiothreitol (DTT) still is a pivotal step in obtaining full sequence coverage of a protein, similar to the one carried out in a bottom-up experiment. However, the use of DTT requires removal before MS analysis, and alternative thiol-free reducing agents also involve laborious sample preparation.

With the current rise of ultrahigh resolution instruments, top-down MS will mature and become widely available [16]. Often, top-down experiments are performed using electrospray 
ionization (ESI) of intact proteins; however, there is also growing interest for in source decay (ISD) during matrixassisted laser desorption ionization (MALDI) [17, 18]. Lowppm mass measurement precision allows a detailed analysis of for instance PTMs, or even all proteoforms [10, 19]. In this context, electrochemical reduction of disulfide bonds can be beneficial for top-down protein sequencing. Recently, it has been shown by the group of Chen that electrochemical reduction of S-S bridges can be performed on-line using desorption electrospray ionization (DESI) [20-23]. In this study, we coupled electrochemistry (EC) to direct infusion ESIMS/MS performed on an ultrahigh resolution Fourier transform ion cyclotron (FTICR) system equipped with a 15 Tesla magnet. On-line EC-liquid chromatography(LC)-MS has become a valuable tool for various applications. The development of special electrodes and electronic systems has opened ways for electrochemical reactions on biomolecules, such as peptides and proteins $[24,25]$. With regard to studies on the oxidative metabolism of drugs, EC has been used for the formation of new chemical entities [26-28]. Furthermore, EC can be used to reduce disulfide bonds in proteins for analytical purposes, as was recently demonstrated for $\beta$-lactoglobulin A and lysozyme [20]. Obviously, the absence of reactants is a major advantage of EC, as well as is the short time scale of interaction with the electrodes. In order to evaluate the performance of such an on-line EC-MS/MS approach, CIDand ETD-spectra of two peptide model systems are compared before and after reduction of disulfide bond(s). It has been shown that through alternating or consecutive use of CID and ETD in bottom-up proteomics LC-MS/MS experiments, based on the decision tree approach, distinct peptide sets are obtained and that the number of protein identifications (IDs) in complex proteomes can be increased [25, 29-32]. An increased peptide sequence has also been reported from simultaneous use of two different fragmentation techniques [33]. Similarly, the use of both fragmentation techniques provides complementary data for middle- and top-down analysis of peptides or proteins. First, the benefits of EC on a relatively simple peptide containing only one disulfide bridge are evaluated. Oxytocin is a small hormone and neurotransmitter with an $\mathrm{S}-\mathrm{S}$ bridge between the cysteine residues at positions 1 and 6 , thus fixing secondary and tertiary structure. Then, on-line EC is evaluated for a more complex middle-down peptide containing four disulfide bridges, namely hepcidin, which is a 25 amino acid-containing hormone that regulates iron metabolism and has a tightly folded hairpin structure [34].

\section{Materials and Methods}

\section{Chemicals}

Oxytocin and hepcidin were purchased from Sigma-Aldrich (Steinheim, Germany) and AnaSpec (San Diego, CA, USA), respectively. HPLC-grade methanol, acetonitrile, isopropanol, and formic acid ( $\geq 95 \%$, purity) were supplied by SigmaAldrich.

\section{Mass Spectrometry}

Direct infusion ESI-FTICR experiments were performed on a Bruker 15 Tesla solariX FTICR mass spectrometer as previously reported $[11,35]$. The experiments were performed using the same instrumental settings with some modifications. Briefly, a quadrupole $(\mathrm{Q})$ was used for precursor ion selection and a hexapole collision cell for CID and ETD. Direct infusion ESI experiments were carried out at an infusion rate of $50 \mu \mathrm{L} / \mathrm{min}$. The ion funnels operated at 100 and $6.0 \mathrm{~V}$, respectively, with the skimmers at 15 and $5 \mathrm{~V}$. The trapping potentials were set at 1.0 and $1.0 \mathrm{~V}$, the analyzer entrance was maintained at $-10 \mathrm{~V}$, and side kick technology was used to further optimize peak shape and signal intensity. The required excitation power was $19 \%$ with a pulse time of $10 \mu \mathrm{s}$. MS/MS-experiments were performed by CID and fragment ion mass analysis in the ICR cell. For these experiments, the collision energy, the accumulation time in the hexapole collision cell, and the isolation window in the Q were optimized for each precursor ion. Collision energies varied from 4.0 to $16.5 \mathrm{~V}$, whereas the accumulation times varied from 0.5 to $10 \mathrm{~s}$. Both the ETD reagent accumulation time and the reaction time were $0.4 \mathrm{~s}$.

\section{Electrochemical Reduction}

Electrochemical reduction of disulfide bond(s) was performed and evaluated on the nine amino acid-containing peptide oxytocin (one disulfide bridge) and the 25 amino acidcontaining peptide hepcidin (four disulfide bridges). An electrochemical cell with titanium-based electrodes ( $\mu$ PrepCell, cell volume $11 \mu \mathrm{L}$; Antec, Zoeterwoude, The Netherlands), controlled by a potentiostat (Roxy Potentiostat, Antec), was used on-line in a direct infusion electrospray ionization (DI-ESI) setup on the FTICR-MS system. Optimal solvent(s) and solvent ratios were determined. Typically, 1-3 $\mu \mathrm{M}$ solutions of the peptide or protein were infused through the PrepCell at a flow rate of $50 \mu \mathrm{L} / \mathrm{min}$. Optimized settings (i.e., times) were used according to manufacturer guidelines (unpublished data), namely a pulse setting with a $1990 \mathrm{~ms}$ interval for E1, followed by a $1010 \mathrm{~ms}$ interval for E2. Activation of the cell was carried out regularly.

\section{Results and Discussion}

\section{On-line EC-MS/MS of Oxytocin}

The set-up of the system is depicted in Figure 1. Oxytocin was directly infused from a syringe pump via the $\mu$-PrepCell into an ultrahigh resolution FTICR mass spectrometer. By switching the EC device on-and-off the disulfide bond in oxytocin either remained intact or was reduced into two SH-groups. First, the ESI solvent conditions were optimized with regard to the MS1 signal intensity and the EC conversion. It was found that a solvent ratio of water and acetonitrile of 90/10 containing $1 \%$ formic acid (FA) was optimal. The use of methanol resulted in a decreased conversion and an increasing amount of organic solvent generally resulted in lower signal intensities. In 


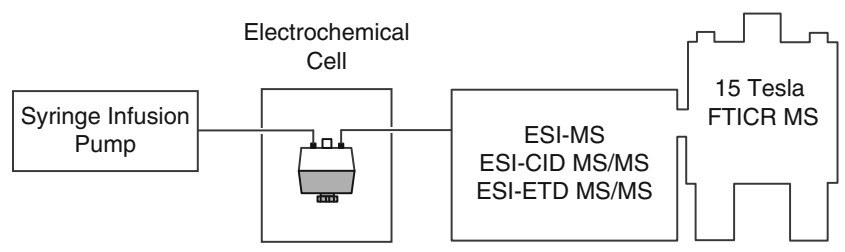

Figure 1. Schematic experimental setup for the reduction of disulfide bonds and on-line infusion into an ultrahigh resolution FTICR mass spectrometer. Collision-induced dissociation (CID) and electron-transfer dissociation (ETD) were used to characterize both native and reduced form of oxytocin and hepcidin

addition, the use of isopropanol gave unstable signal and conversion (data not shown). Next, the E1 and E2 potentials were evaluated for the on-line reduction of oxytocin, using pulse settings as described in the Materials and Methods section. The results are plotted in Figure 2a. From this Figure it becomes clear that with decreasing E1 (i.e., from -1 to $-3 \mathrm{~V}$ ), the amount of "native" (S-S bridge containing) oxytocin decreases, and that with increasing E2 (i.e., from +1 to $+2 \mathrm{~V}$ ) the signal of reduced oxytocin is enhanced. It was found that further increase of E2 resulted in a (small) decrease of reduced oxytocin. As can be seen from Figure 2a, the maximum conversion of oxytocin into its reduced form was approximately $80 \%$ at $\mathrm{E} 2=2.2 \mathrm{~V}$.

Note that the ultrahigh resolving power of the FTICR system allowed the detailed analysis of two overlapping isotopic profiles of the doubly protonated molecular ions of native $\left(\left[\mathrm{M}+2 \mathrm{H}^{+}\right]^{2+}\right)$ and reduced oxytocin $\left(\left[\mathrm{M}+2 \mathrm{H}+2 \mathrm{H}^{+}\right]^{2+}\right.$, further referred to as $\left(\left[\mathrm{M}_{\text {red }}+2 \mathrm{H}^{+}\right]^{2+}\right)$. The differences within the third isotopic peak at approximately $m / z 505.2$ are shown in Figure $2 b$. In the case of native oxytocin, this signal consists of two peaks attributable to the presence or absence of a ${ }^{34} \mathrm{~S}$ isotope, with a difference of 5.6 milli-mass units (left-hand panel of Figure 2b). In the case of reduced oxytocin, the corresponding signal at $\mathrm{m} / \mathrm{z} 505.2$ has turned into a monoisotopic signal and, thus, contains only one peak, which is observed at 4.3 milli-mass units higher than the third isotopic peak of doubly protonated native oxytocin (right-hand panel of Figure $2 \mathrm{~b}$ ). Both species are present when the on-line reduction

(a)
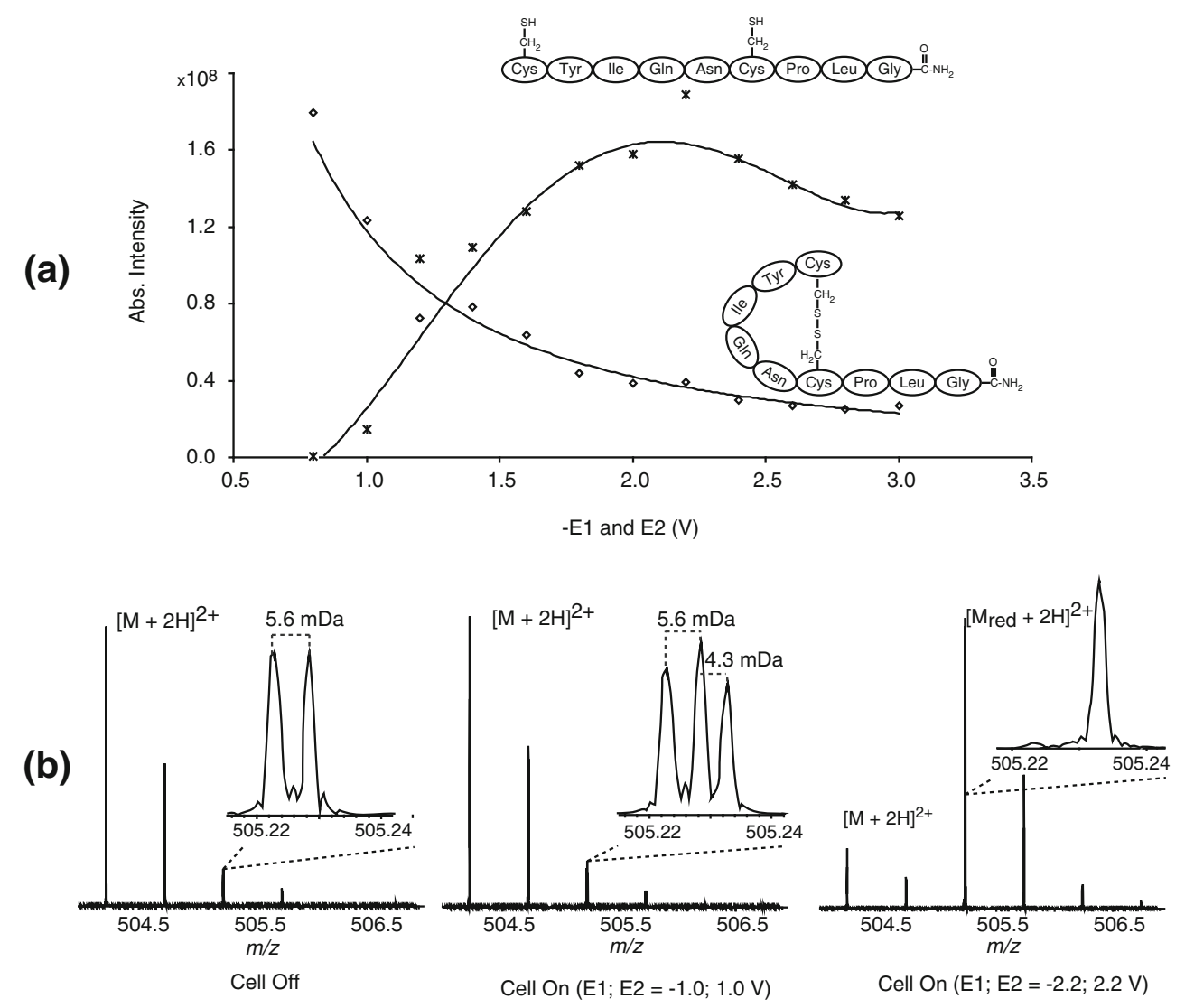

Figure 2. Evaluation of the $\mu$-PrepCell potentials for the on-line reduction of the disulfide bridge of oxytocin (a). The maximum conversion rate of approximately $80 \%$ was obtained at E1 $=-2.2 \mathrm{~V}$ and $\mathrm{E} 2=2.2 \mathrm{~V}$. Evaluation of the conversion rate (red-ox) monitoring the signal intensity of the doubly charged oxytocin (b) measured with a resolving power of 250,000 . The two overlapping isotopic profiles of the doubly protonated molecular ions of native $\left(\left[\mathrm{M}+2 \mathrm{H}^{+}\right]^{2+}\right.$; left-hand panel) and reduced oxytocin $\left(\left[\mathrm{M}_{\text {red }}+2 \mathrm{H}^{+}\right]^{2+}\right.$; right-hand panel) were resolved. The case of a partial reduction of oxytocin is shown in the middle panel. Here, three peaks are resolved at $\mathrm{m} / \mathrm{z} 505.2$ shown in the enlarged part, corresponding to the third isotopic peak of [M + $\left.2 \mathrm{H}^{+}\right]^{2+}$ with ${ }^{34} \mathrm{~S}$ and ${ }^{13} \mathrm{C}_{2}$, respectively, and the monoisotopic peak of $\left[\mathrm{M}_{\text {red }}+2 \mathrm{H}^{+}\right]^{2+}$ 
of the disulfide bond is not complete, exemplified by the overlap of two isotopic profiles (middle panel of Figure 2b).

Subsequently, the system as depicted in Figure 1 was used to generate $\mathrm{MS} / \mathrm{MS}$-data from both native and reduced oxytocin. The CID spectrum of doubly protonated native oxytocin is depicted in Figure 3, as well as the one that was obtained after on-line reduction of the $\mathrm{S}-\mathrm{S}$ bridge. The large majority of fragment ions could be explained from "standard" $b / y$-fragmentation, including neutral losses. In addition, a few ions were assigned as $a$-ions or as internal fragments resulting from two-bond cleavages. The fragment ions observed from native oxytocin, and the resulting sequence coverage, were in good agreement with previously obtained data from sustained off-resonance induced (SORI) CID-experiments, with dominant cleavages of the three amino acid "tail" and minor fragmentation of the six amino acid-containing ring ("tocin ring") [36]. The only noticeable difference between the current and the SORI-CID data was the absence of a $b_{3}$-ion in the CID

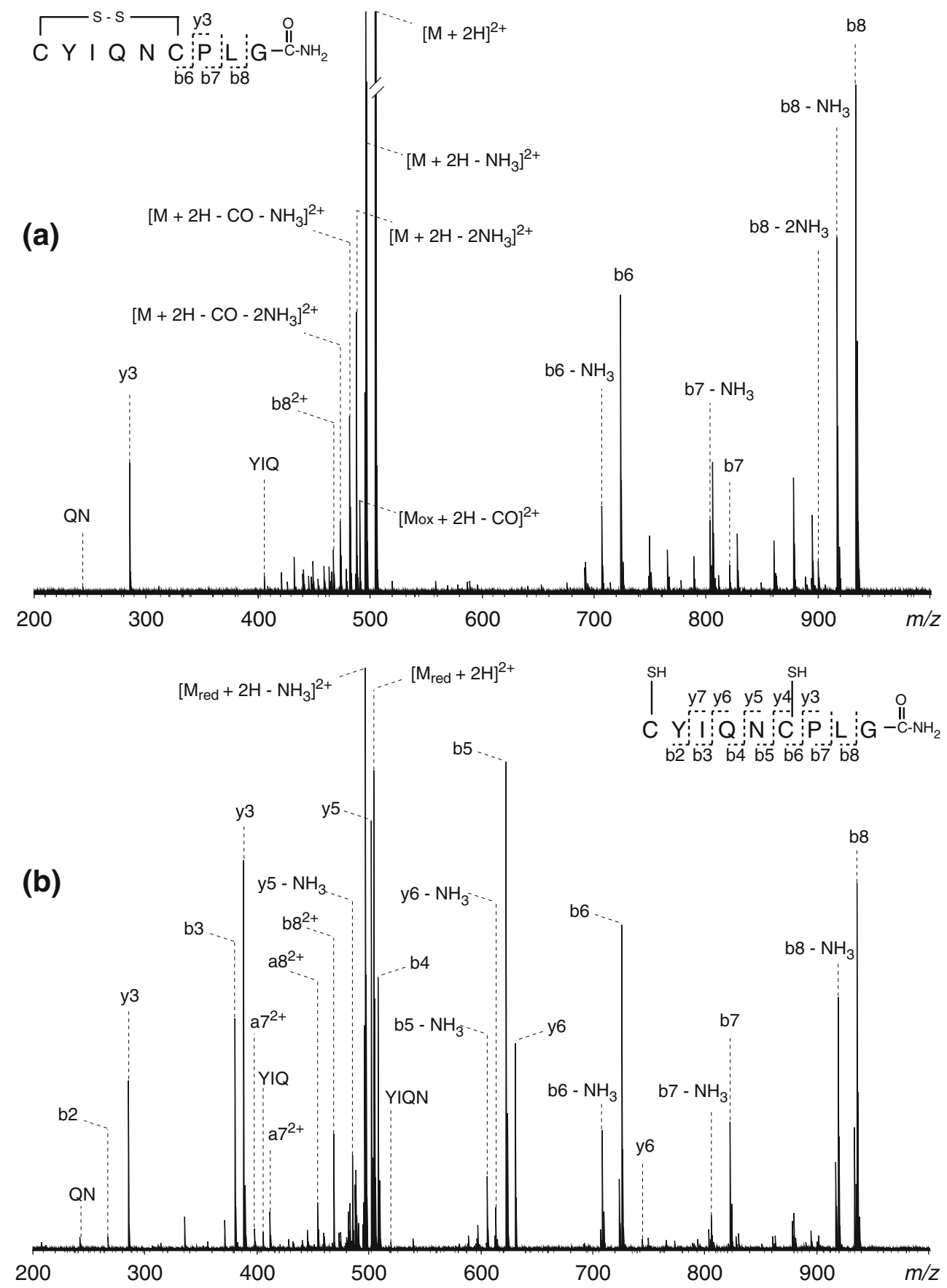

Figure 3. CID spectrum of doubly protonated native (a) and on-line reduced (b) oxytocin. The online reduction results in a richer MS/MS spectrum and, consequently, a more comprehensive characterization of the peptide sequence 
spectrum of native oxytocin, next to variation in the ion abundances. From the comparison of the CID spectra of native and reduced oxytocin, it becomes evident that many additional fragment ions from tocin-ring cleavages have appeared after the on-line EC reduction of the $\mathrm{S}-\mathrm{S}$ bridge (e.g., $b_{2} / y_{7}, b_{3} / y_{6}$, $b_{4}\left(y_{5}, b_{5} / y_{4}\right)$. As a result, the sequence coverage of oxytocin has improved more than 2-fold. Similarly, the application of ETD yielded large differences between fragmentation spectra of native and reduced oxytocin. This is depicted in Figure 4 The benefits in terms of sequence coverage are not as obvious as in the case of CID spectra, albeit that the number of sequenceinformative fragment ions doubled from 8 to 16 and that the total number of (assigned) fragment ions was higher for the reduced species. Upon comparison of the ETD spectrum of
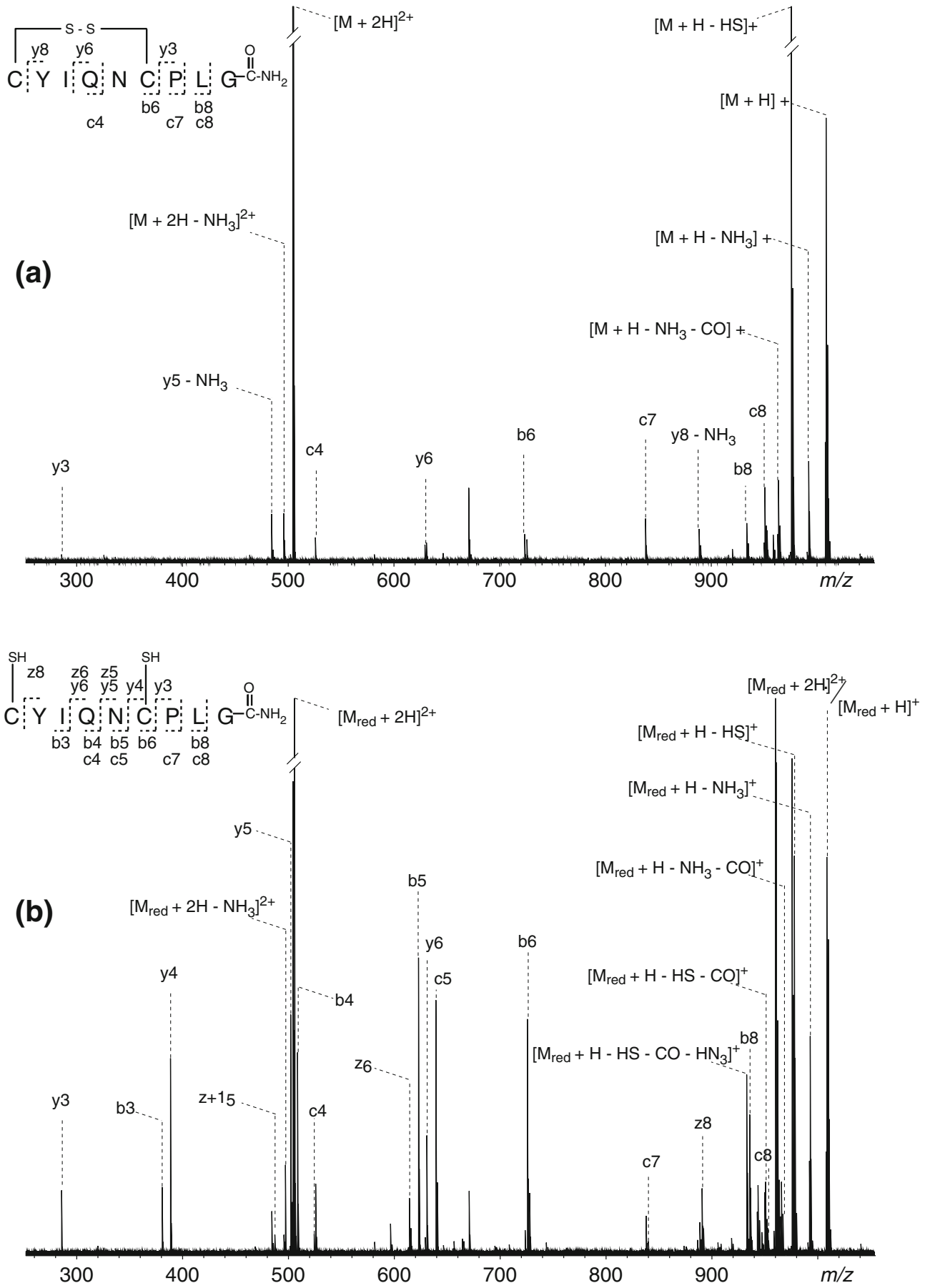

Figure 4. ETD spectrum of doubly protonated native (a) and on-line reduced (b) oxytocin. The differences between the two spectra are less apparent than in the case of CID spectra. The on-line reduction of the disulfide bridge results in a more comprehensive characterization of the tocin-ring 
(a)

isolated precursor ion; CELL OFF

I

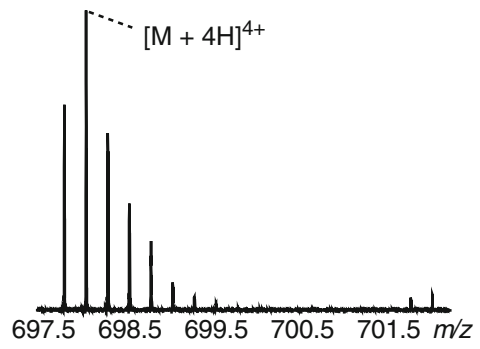

ESI-FTICR MS/MS

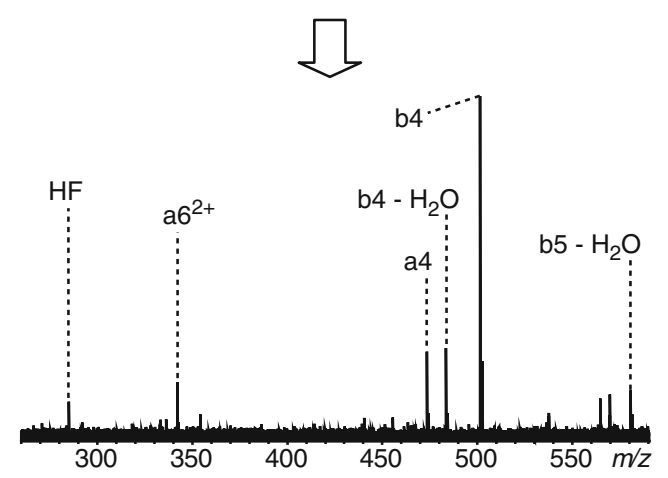

II
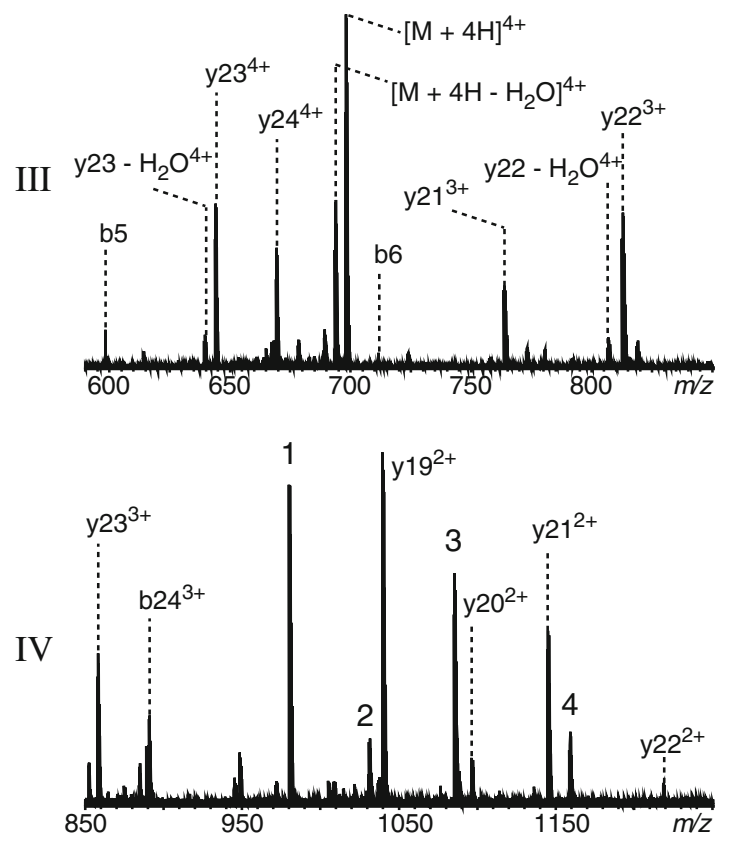

(b)

isolated precursor ion; CELL ON

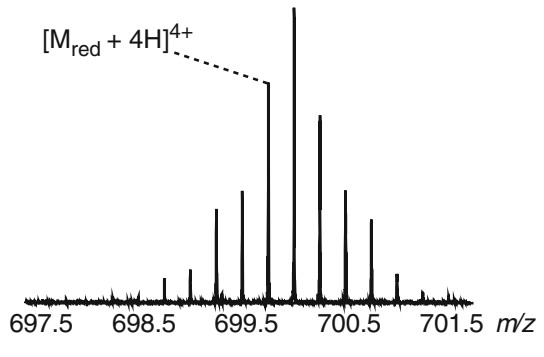

ESI-FTICR MS/MS<smiles>C1CCCCC1</smiles>
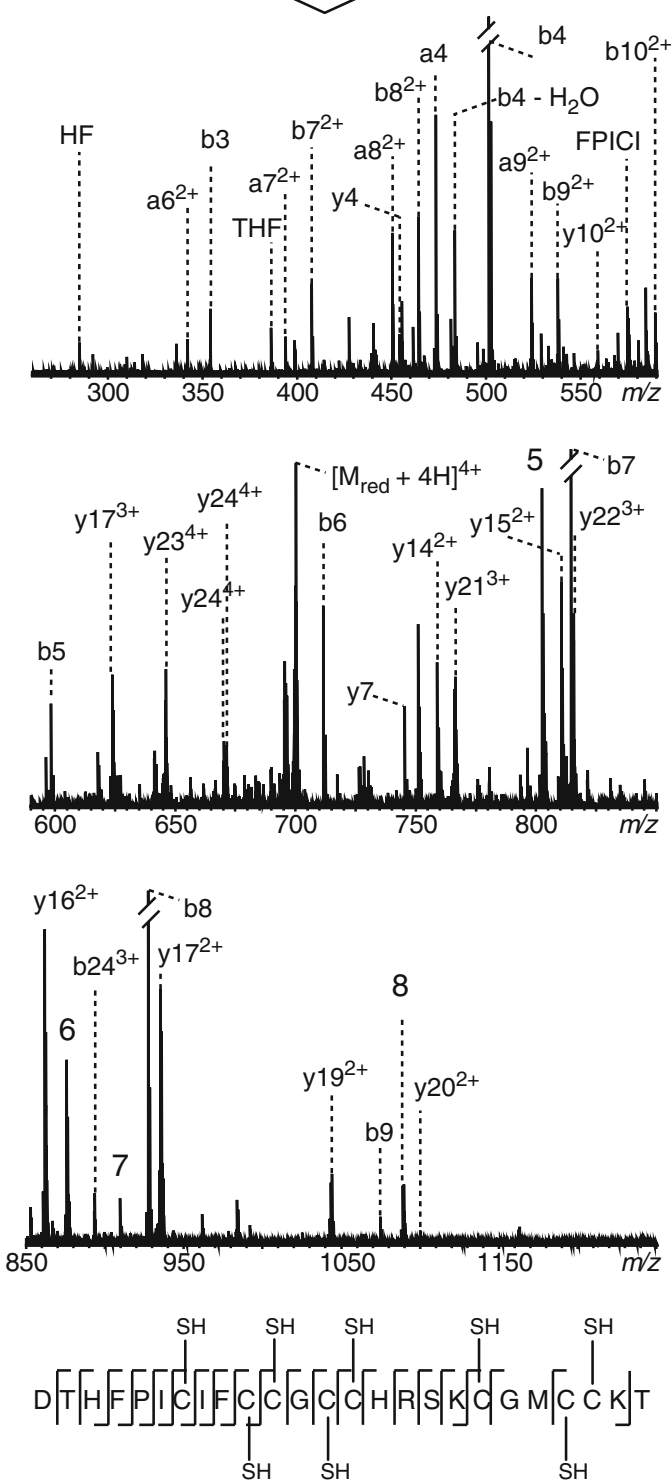

Figure 5. CID spectrum of native (A-I, -II, -III, -IV, and -V) and on-line reduced (B-I, -II, -III, -IV, and -V) hepcidin. The fragmentation of the native hepcidin led to backbone cleavages that are not involved in the region containing the four disulfide bonds. The on-line reduction of the four S-S bridges prior the MS/MS experiment led to a more extensive fragmentation resulting in 21 out of 24 cleaved peptide bonds. The following internal fragments were also observed as doubly charged ions: (1) CIFCCGCCHRSKCGMCCK; (2) CIFCCGCCHRSKCGMCCK; (3) PICIFCCGCCHRSKCGMCCK; (4) FPICIFCCGCCHRSKCGMCCK; (5) CCGCCHRSKCGMCCK; (6) FCCGCCHRSKCGMCCK; (7) CIFCCGCCHRSKCGMCCK; (8) PICIFCCGCCHRSKCGMCCK 
doubly protonated native oxytocin with previous results obtained from ECD experiments, it was noted that the type of fragments were the same, i.e. typical $b / y$ fragments and typical $c$-fragments [36]. Interestingly, the number of tocin-ring cleavages was lower in ETD than in ECD spectra: $b_{3^{-}}, b_{5^{-}}$, and $c_{5^{-}}$-ions were absent in ETD, as well as $y_{4^{-}}, y_{5^{-}}$and $y_{7}$-ions. On the other hand, in the ETD spectra, "new" $y_{8^{-}}, b_{8^{-}}, c_{7^{-}}$, and $c_{8^{-}}$ions were observed. It was further noted that both $b / y$ - and $c / z$ fragments were observed in the ETD spectrum of ECreduced, doubly protonated oxytocin. This is somewhat different from the previous ECD results, in which reduced and carboxymethylated doubly protonated oxytocin yielded solely $b / y$-fragments.

\section{On-line EC-MS/MS of Hepcidin}

The system depicted in Figure 1 was used for a topdown analysis of the 25 amino acid-containing hormone hepcidin. The CID spectrum of native hepcidin was recorded, showing mostly typical $b / y$-fragments and a few $a$-fragment ions. From the sequence coverage shown in Figure 5, it becomes clear that the observed fragment ions resulted solely from peptide backbone cleavages that are not involved in the region containing the four disulfide bonds. In other words, the disulfide bonds clearly hamper sequencing the part from Cys7 to Cys23. After on-line electrochemical reduction of all four S-S bridges, the CID spectrum contained many more fragment ions, as can be seen in Figure 5. The MS/MS-data are still dominated by $b$ - and $y$-fragments and, in addition, more internal fragments were observed (resulting from twobond cleavages). The beneficial effect of using on-line EC becomes clear from the sequence coverage: only seven bonds were fragmented in the native species, whereas 21 out of 24 peptide bonds were cleaved in the fully reduced hepcidin. Previous MS identifications of hepcidin were based mostly on (accurate) mass measurements [34, 37]. To our knowledge, this is the first study where such high sequence coverage of hepcidin was obtained, although LCMS/MS methods have been used to identify and quantify hepcidin in body fluids [38, 39].

In summary, the presented study here shows that disulfide bridges can be successfully reduced in an online ESI set-up using electrochemistry. These findings are similar to those obtained by other authors using DESI [20-22]. It will be of great interest to further study the coupling of EC with LC-based separation of proteins and on-line digestion, as this might finally lead to a fully integrated workflow overcoming the reduction/alkylation step in standard bottom-up proteomics. In addition, the coupling of EC with LC-based peptide separation may open new avenues in the field of de novo and middledown sequencing of (large) peptides.

\section{Open Access}

This article is distributed under the terms of the Creative Commons Attribution License which permits any use, distribution, and reproduction in any medium, provided the original author(s) and the source are credited.

\section{References}

1. Aebersold, R., Mann, M.: Mass spectrometry-based proteomics. Nature 422, 198-207 (2003)

2. Nilsson, T., Mann, M., Aebersold, R., Yates, J.R., Bairoch, A., Bergeron, J.J.M.: Mass spectrometry in high-throughput proteomics: ready for the big time. Nat. Method 7, 681-685 (2010)

3. Angel, T.E., Aryal, U.K., Hengel, S.M., Baker, E.S., Kelly, R.T., Robinson, E.W., Smith, R.D.: Mass spectrometry-based proteomics: existing capabilities and future directions. Chem. Soc. Rev. 41, 39123928 (2012)

4. Switzar, L., Giera, M., Niessen, W.M.A.: Protein digestion: an overview of the available techniques and recent developments. J. Proteome Res. 12, 1067-1077 (2013)

5. Duncan, M.W., Aebersold, R., Caprioli, R.M.: The pros and cons of peptide-centric proteomics. Nat. Biotechnol. 28, 659-664 (2010)

6. Kelleher, N.L., Lin, H.Y., Valaskovic, G.A., Aaserud, D.J., Fridriksson, E.K., McLafferty, F.W.: Top down versus bottom up protein characterization by tandem high-resolution mass spectrometry. J. Am. Chem. Soc. 121, 806-812 (1999)

7. Siuti, N., Kelleher, N.L.: Decoding protein modifications using topdown mass spectrometry. Nat. Methods 4, 817-821 (2007)

8. Tran, J.C., Zamdborg, L., Ahlf, D.R., Lee, J.E., Catherman, A.D., Durbin, K.R., Tipton, J.D., Vellaichamy, A., Kellie, J.F., Li, M., Wu, C., Sweet, S.M.M., Early, B.P., Siuti, N., LeDuc, R.D., Compton, P.D., Thomas, P.M., Kelleher, N.L.: Mapping intact protein isoforms in discovery mode using top-down proteomics. Nature 480, 254-258 (2011)

9. Calligaris, D., Villard, C., Lafitte, D.: Advances in top-down proteomics for disease biomarker discovery. J. Proteom. 74, 920-934 (2011)

10. Nicolardi, S.; Dalebout, H.; Bladergroen, M.R.; Mesker, W.E.; Tollenaar, R.A.E.M.; Deelder, A.M.; van der Burgt, Y.E.M.: Identification of human serum peptides in fourier transform ion cyclotron resonance precision profiles. Int. J. Proteom. 804036, (2012)

11. Alegre-Cebollada, J., Kosuri, P., Rivas-Pardo, J.A., Fernández, J.M.: Direct observation of disulfide isomerization in a single protein. Nat. Chem. 3, 882-887 (2011)

12. Roepstorff, P., Fohlman, J.: Proposal for a common nomenclature for sequence ions in mass spectra of peptides. Biomed. Mass Spectrom. 11, 601 (1984)

13. Zubarev, R.A., Kruger, N.A., Fridriksson, E.K., Lewis, M.A., Horn, D.M., Carpenter, B.K., McLafferty, F.W.: Electron capture dissociation of gaseous multiply-charged proteins is favored at disulfide bonds and other sites of high hydrogen atom affinity. J. Am. Chem. Soc. 121, 2857-2862 (1999)

14. Syka, J.E.P., Coon, J.J., Schroeder, M.J., Shabanowitz, J., Hunt, D.F.: Peptide and protein sequence analysis by electron transfer dissociation mass spectrometry. Proc. Natl. Acad. Sci. U.S.A. 101, 9528-9533 (2004)

15. Kleinnijenhuis, A.J., Duursma, M.C., Breukink, E., Heeren, R.M.A., Heck, A.J.R.: Localization of intramolecular monosulfide bridges in lantibiotics determined with electron capture induced dissociation. Anal. Chem. 75, 3219-3225 (2003)

16. Zubarev, R.A., Makarov, A.A.: Orbitrap mass spectrometry. Anal. Chem. 85, 5288-5296 (2013)

17. Demeure, K., Quinton, L., Gabelica, V., De Pauw, E.: Rational selection of the optimum MALDI matrix for top-down proteomics by in-source decay. Anal. Chem. 79, 8678-8685 (2007)

18. Resemann, A., Wunderlich, D., Rothbauer, U., Warscheid, B., Leonhardt, H., Fuchser, J., Kuhlmann, K., Suckau, D.: Top-down de novo protein sequencing of a $13.6 \mathrm{kDa}$ camelid single heavy chain antibody by matrix-assisted laser desorption ionization-time- 
of-flight/time-of-flight mass spectrometry. Anal. Chem. 82, 3283$3292(2010)$

19. Kelleher, N.: A cell-based approach to the human proteome project. J. Am. Soc. Mass Spectrom. 23, 1617-1624 (2012)

20. Zhang, Y., Cui, W., Zhang, H., Dewald, H.D., Chen, H.: Electrochemistry-assisted top-down characterization of disulfide-containing proteins. Anal. Chem. 84, 3838-3842 (2012)

21. Zhang, Y., Dewald, H.D., Chen, H.: On-line mass spectrometric analysis of proteins/peptides following electrolytic cleavage of disulfide bonds. J. Proteome Res. 10, 1293-1304 (2011)

22. Lu, M., Wolff, C., Cui, W., Chen, H.: Investigation of some biologically relevant redox reactions using electrochemical mass spectrometry interfaced by desorption electrospray ionization. Anal. Bioanal. Chem. 403, 355-365 (2012)

23. Zhang, Y., Yuan, Z., Dewald, H.D., Chen, H.: Coupling of liquid chromatography with mass spectrometry by desorption electrospray ionization (DESI). Chem. Commun. 47, 4171-4173 (2011)

24. Permentier, H.P., Bruins, A.P.: Electrochemical oxidation and cleavage of proteins with on-line mass spectrometric detection: development of an instrumental alternative to enzymatic protein digestion. J. Am. Soc. Mass Spectrom. 15, 1707-1716 (2004)

25. Roeser, J., Permentier, H.P., Bruins, A.P., Bischoff, R.: Electrochemical oxidation and cleavage of tyrosine- and tryptophan-containing tripeptides. Anal. Chem. 82, 7556-7565 (2010)

26. Falck, D., Vlieger, J., Giera, M., Honing, M., Irth, H., Niessen, W., Kool, J.: On-line electrochemistry-bioaffinity screening with parallel HR-LC-MS for the generation and characterization of modified p38 $\alpha$ kinase inhibitors. Anal. Bioanal. Chem. 403, 367-375 (2012)

27. Jahn, S., Karst, U.: Electrochemistry coupled to (liquid chromatography/) mass spectrometry-Current state and future perspectives. J. Chromatogr. A 1259, 16-49 (2012)

28. Nouri-Nigjeh, E., Bischoff, R., Bruins, A.P., Permentier, H.P.: Electrochemistry in the mimicry of oxidative drug metabolism by cytochrome P450s. Curr. Drug Metab. 12, 359-371 (2011)

29. Swaney, D.L., McAlister, G.C., Coon, J.J.: Decision tree-driven tandem mass spectrometry for shotgun proteomics. Nat. Methods 5, 959-964 (2008)

30. Hogan, J.M., Pitteri, S.J., Chrisman, P.A., McLuckey, S.A.: Complementary structural information from a tryptic $\mathrm{N}$-linked glycopeptide via electron transfer ion/ion reactions and collision-induced dissociation. J. Proteome Res. 4, 628-632 (2005)

31. Frese, C.K., Altelaar, A.F.M., Hennrich, M.L., Nolting, D., Zeller, M., Griep-Raming, J., Heck, A.J.R., Mohammed, S.: Improved peptide identification by targeted fragmentation using CID, HCD, and ETD on an LTQ-Orbitrap Velos. J. Proteome Res. 10, 2377-2388 (2011)

32. Shen, Y., Tolić, N., Xie, F., Zhao, R., Purvine, S.O., Schepmoes, A.A., Moore, R., Anderson, G.A., Smith, R.D.: Effectiveness of CID, HCD, and ETD with FT MS/MS for degradomic-peptidomic analysis: comparison of peptide identification methods. J. Proteome Res. 10, 3929-3943 (2011)

33. Mihalca, R., van der Burgt, Y.E.M., McDonnell, L.A., Duursma, M. Cerjak, I., Heck, A.J.R., Heeren, R.M.A.: Combined infrared multiphoton dissociation and electron-capture dissociation using co-linear and overlapping beams in Fourier transform ion cyclotron resonance mass spectrometry. Rapid Commun. Mass Spectrom. 20, 1838-1844 (2006)

34. Kroot, J.J.C., Tjalsma, H., Fleming, R.E., Swinkels, D.W.: Hepcidin in human iron disorders: diagnostic implications. Clin. Chem. 57, 16501669 (2011)

35. Nicolardi, S., van der Burgt, Y.E., Wuhrer, M., Deelder, A.M.: Mapping O-glycosylation of apolipoprotein C-III in MALDI-FT-ICR protein profiles. Proteomics 13, 992-1001 (2013)

36. van der Burgt, Y.E.M., Palmblad, M., Dalebout, H., Heeren, R.M.A., Deelder, A.M.: Electron capture dissociation of peptide hormone changes upon opening of the tocin ring and complexation with transition metal cations. Rapid Commun. Mass Spectrom. 23, 31-38 (2009)

37. Tjalsma, H., Laarakkers, C.M., van Swelm, R.P., Theurl, M., Theurl, I., Kemna, E.H., van der Burgt, Y.E., Venselaar, H., Dutilh, B.E., Russel, F.G., Weiss, G., Masereeuw, R., Fleming, R.E., Swinkels, D.W.: Mass spectrometry analysis of hepcidin peptides in experimental mouse models. PLoS One 6, e16762 (2011)

38. Murphy, A.T., Witcher, D.R., Luan, P., Wroblewski, V.J.: Quantitation of hepcidin from human and mouse serum using liquid chromatography tandem mass spectrometry. Blood 110, 1048-1054 (2007)

39. Bansal, S.S., Abbate, V., Bomford, A., Halket, J.M., Macdougall, I.C., Thein, S.L., Hider, R.C.: Quantitation of hepcidin in serum using ultra-high-pressure liquid chromatography and a linear ion trap mass spectrometer. Rapid Commun. Mass Spectrom. 24, 12511259 (2010) 